\title{
Nucleus Drop or Intraocular Lens Drop Underwent Pars Plana Vitrectomy Due to Complication of Cataract Surgery
}

Noviana Kurniasari Vivin ${ }^{1}$, Ari Djatikusumo², Elvioza², Gitalisa Andayani², Anggun Rama Yudantha², Mario Marbungaran Hutapea ${ }^{2}$, Andi Arus Victor ${ }^{2}$

${ }^{1}$ RS Mata Undaan, Surabaya, East Java

${ }^{2}$ Department of Ophthalmology, Faculty of Medicine, Universitas Indonesia dr. Cipto Mangunkusumo National General Hospital, Jakarta

\begin{abstract}
Background: The incidence of nucleus drop or intraocular lens (IOL) drop as the complication of phacoemulsification increases concomitant to the increased frequency of phacoemulsification. Pars plana vitrectomy (PPV) followed by endofragmentation and secondary $1 O L$ implantation is the choice of management procedure. This study aims to determine the frequency, outcome, and complication of PPV in the case of nucleus drop or IOL drop in the Department of Ophthalmology, dr. Cipto Mangunkusumo Hospital, Jakarta
\end{abstract}

Methods: This study is a retrospective descriptive study conducted in the Vitreoretinal Division of the Department of Ophthalmology, dr. Cipto Mangunkusumo Hospital, Jakarta. Research data were collected from medical records of patients with nucleus drop or IOL drop underwent PPV in January-December 2017.

Results: There were 19 cases studied. The incidence of nucleus drop occurred in phacoemulsification surgery techniques (94.7\%) and ECCE techniques (5.3\%). Vitrectomy surgery was performed $\leq 2$ weeks in $31.6 \%$ and $>2$ weeks in $68.4 \%$ after the first arrival at the vitreoretinal clinic. Most pre-PPV visual acuity (VA) was 1/60-6/60 (47.1\%). In the final follow-up, there was an improvement in visual acuity of 6/45-6/6 with a final percentage of $42.2 \%$. Complications after PPV and secondary IOL implantation include elevated IOP (10.5\%), IOL decentration (5.3\%), corneal decompensation (5.3\%), macular edema (5.3\%), and retinal detachment (5.3\%).

Conclusion: Nucleus drop or IOL drop generally occurs in phacoemulsification cataract surgery techniques. Improvement of VA achieved after PPV and secondary $1 O \mathrm{~L}$ implantation at the end of the follow-up period. The most common post-PPV complication is elevated IOP.

Keywords: Nucleus Drop, IOL drop, Pars Plana Vitrectomy, Complication of Cataract Surgery Cite This Article: VIVIN, Noviana Kurniasari et al. Nucleus Drop or Intraocular Lens Drop Underwent Pars Plana Vitrectomy due to Complication of Cataract Surgery. International Journal of Retina, [S.I.], v. 2, n. 2, sep. 2019. ISSN 2614-8536. Available at: https://www.ijretina.com/index.php/ijretina/article/view/73 https://doi.org/10.35479/ijretina.2019.vol002.iss002.73

\section{INTRODUCTION}

*Correspondence to:

Andi Arus Victor,

Faculty of Medicine, Universitas

Indonesia

dr. Cipto Mangunkusumo

National General Hospital,

Jakarta

arvimadao@yahoo.com
Cataract is a major cause of blindness throughout the world. The increase in frequency of phacoemulsification as a method of cataract surgery causes an increased incidence of surgical complication such as vitreous loss, posterior capsule rupture, nucleus drop, and intraocular lens (IOL) drop. The incidence of nucleus drop is about $0.09-0.8 \% .^{1}$ Factors affecting the nucleus drop include operator experience, the surgical technique, complicated cataract conditions such as posterior polar cataracts and hard nuclear cataracts, history of trauma, history of vitrectomy surgery, high myopia, zonular weakness, and floppy iris syndrome. ${ }^{2,3}$ 
Dropped nucleus or dropped IOL after cataract surgery potentially causing serious complication. ${ }^{4}$ Therefore, the right timing of operation for nucleus drop or IOL drop is very important to prevent visual loss. ${ }^{2,5}$ The nucleus that falls into the vitreous cavity must be removed, unless for the small-sized nucleus and no inflammation occured. ${ }^{6}$ The most commonly used surgical technique is 3-port pars plana vitrectomy (PPV) to remove the vitreous around the nucleus followed by fragmentation using fragmatome or lifting the dropped IOL through the scleral/corneal tunnel.6, 7 Perfluorocarbon fluid (heavy fluid) can also be used to lift/push the nucleus or $1 O L$ upward in the vitreous cavity. The choice of procedure to remove the nucleus or $\mathrm{IOL}$ is very dependent on the expertise of the surgeon. This study aims to determine the frequency, outcome, and complication of PPV surgery in cases of nucleus drop or IOL drop in the Department of Ophthalmology, dr. Cipto Mangunkusumo Hospital, Jakarta in 2017.

\section{METHODS}

This research is a retrospective descriptive study carried out in the Vitreoretinal Division of the Department of Ophthalmology, dr. Cipto Mangunkusumo Hospital, Jakarta. Data were collected from medical records of patients with nucleus drop or IOL drop underwent PPV in the period January-December 2017. Patients with incomplete medical record data will be excluded from this study.

Pre-PPV BCVA is the best correction of visual acuity before PPV surgery which measured by Snellen chart. Post-PPV BCVA is the best correction of visual acuity after PPV or secondary IOL implantation which measured by Snellen charts. Secondary $\mathrm{IOL}$ implantation is an intraocular lens insertion surgery performed in conjunction with PPV or at a different time. The PPV time interval is the period from diagnosis to the date of operation. Postoperative complications are unexpected conditions after the surgery.

\section{RESULTS}

There were 19 patients underwent PPV due to nucleus drop or IOL drop.

Table 1. Characteristics of patients who underwent PPV

\begin{tabular}{lll}
\hline Variable & Frequency & Percentage (\%) \\
\hline Gender $(\mathbf{n}=19)$ & & \\
$\quad$ Male & 13 & 68.5 \\
Female & 6 & 31.4 \\
Age $(\mathbf{n}=19)$ & & \\
\hline
\end{tabular}

\begin{tabular}{|c|c|c|}
\hline $40-50$ & 1 & 5.3 \\
\hline $51-60$ & 8 & 42.1 \\
\hline $61-70$ & 7 & 36.8 \\
\hline $71-80$ & 3 & 15.8 \\
\hline \multicolumn{3}{|l|}{ Lateralisation ( $n=19$ ) } \\
\hline OD & 10 & 54 \\
\hline os & 9 & 45 \\
\hline \multicolumn{3}{|l|}{ Cases (n=19) } \\
\hline Nucleus Drop & 13 & 68.5 \\
\hline IOL Drop & 6 & 31.4 \\
\hline \multicolumn{3}{|l|}{$\begin{array}{l}\text { Surgical technique } \\
(n=19)\end{array}$} \\
\hline Phacoemulsification & 18 & 94.7 \\
\hline ECCE & 1 & 5.3 \\
\hline \multicolumn{3}{|l|}{$\begin{array}{l}\text { Types of procedure } \\
(n=19)\end{array}$} \\
\hline $\begin{array}{l}\text { Vitrectomy+ } \\
\text { EF+EL+TA injection }\end{array}$ & 11 & 57.9 \\
\hline $\begin{array}{l}\text { Vitrectomy } \\
\text { +EF+EL+SO+ TA } \\
\text { injection }\end{array}$ & 2 & 10.5 \\
\hline $\begin{array}{l}\text { Vitrectomy +EL+IOL } \\
\text { explantation+ TA } \\
\text { injection }\end{array}$ & 4 & 21.1 \\
\hline Vitrectomy & 2 & 10.5 \\
\hline$+\mathrm{EF}+\mathrm{EL}+\mathrm{IOL}$ & & \\
\hline $\begin{array}{l}\text { explantation+ TA } \\
\text { injection }\end{array}$ & & \\
\hline \multicolumn{3}{|l|}{$\begin{array}{l}\text { PPV time interval } \\
(n=19)\end{array}$} \\
\hline$\leq 2$ weeks & 6 & 31.6 \\
\hline$>2$ weeks & 13 & 68.4 \\
\hline \multicolumn{3}{|l|}{$\begin{array}{l}\text { Location of secondary } \\
\text { IOL implantation } \\
\text { ( } n=19)\end{array}$} \\
\hline Iris claw & 10 & 52.6 \\
\hline Scleral fixation & 3 & 15.8 \\
\hline Sulcus & 6 & 31.6 \\
\hline
\end{tabular}

$\mathrm{EF}=$ Endofragmentation, EL=Endolaser, $\mathrm{TA}$

Injection=Triamcinolone Acetonide Injection, SO=Silicon Oil

Based on table 1, the majority of subjects was male (68.5\%), compared to female (31.4\%). Out of the 19 cases, there were 13 cases (68.5\%) of nucleus drop and 6 cases of IOL drop (31.4\%). Based on surgical technique, cases of nucleus drop commonly occurred in phacoemulsification cataract surgery technique $(94.7 \%)$, while in ECCE technique only occurred in $5.3 \%$ of cases. Triamcinolone acetonide injection was done in every nucleus drop or IOL drop patient who underwent PPV. The majority of vitrectomy operations performed $>2$ weeks in 13 eyes, and the most common location of the secondary $\mathrm{IOL}$ implantation was iris claw. 


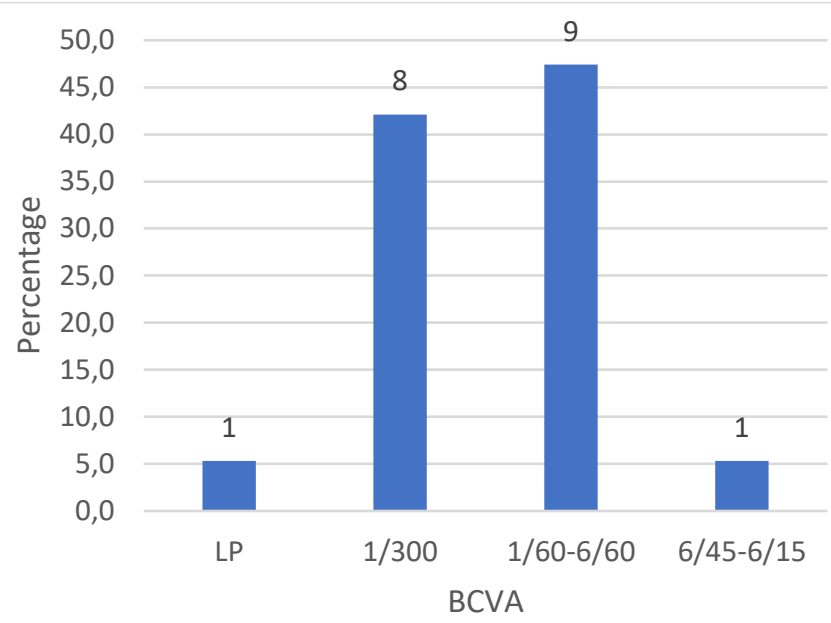

Figure 1. The frequency of pre-PPV BCVA

Figure 1 and 2 show the frequency of changes in visual acuity before PPV and after follow-up. The highest proportion of pre-PPV BCVA was in group 1/60-6/60 (47.1\%). The patient with pre-PPV BCVA of $>6 / 45$ was only 1 patient (5.3\%), while patients with post-PPV BCVA of $>6 / 45$ was 8 patients $(42.2 \%)$, which 4 patients $(21.1 \%)$ with visual acuity between $6 / 45-6 / 15$ and 4 patients (21.1\%) with visual acuity between 6/12-6/6.

Table 2. Pre-PPV condition and post-PPV complications

\begin{tabular}{lll}
\hline Variable & Frequency & Percentage(\%) \\
\hline $\begin{array}{l}\text { Pre-PPV condition ( } \mathbf{n}=19) \\
\text { Elevated IOP }\end{array}$ & 3 & 15.8 \\
Corneal edema & 3 & 15.8 \\
Uveitis & 1 & 5.3 \\
Macular edema & 1 & 5.3 \\
Retinal detachment & 1 & 5.3 \\
& & \\
Post-PPV complications & & \\
( $\mathbf{n}=19)$ & & \\
Elevated IOP & 2 & 10.5 \\
IOL decentration & 1 & 5.3 \\
Corneal decompensation & 1 & 5.3 \\
Macular edema & 1 & 5.3 \\
Retinal Detachment & 1 & 5.3 \\
\hline
\end{tabular}

After PPV and secondary IOL implantation, several complications were found, including elevated IOP in 2 patients (10.5\%), IOL decentration in 1 patient (5.3\%), corneal decompensation in 1 patient (5.3\%), macular edema in 1 patient (5.3\%), and retinal detachment in 1 patient (5.3\%).

\section{DISCUSSION}

The incidence of nucleus drop after cataract surgery has been increasing as the use of phacoemulsification increases. Even though several studies reported the

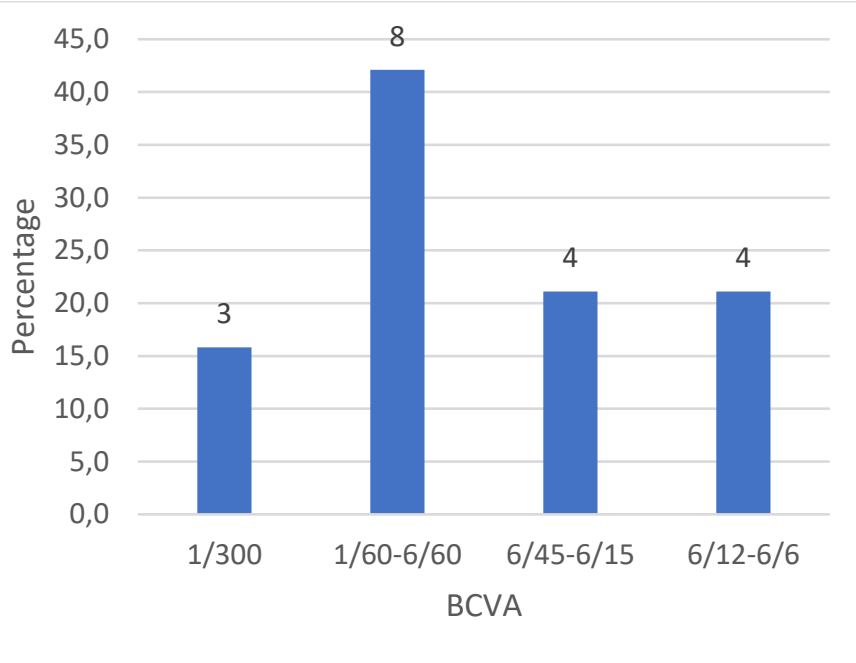

Figure 2. The frequency of post-PPV BCVA

incidence of nucleus drop as low as $0.09-0.8 \%$, it is potentially threatening the vision if it is not handled appropriately. ${ }^{1}$ In this study, as high as $94.7 \%$ of nucleus drop cases were found after cataract surgery using phacoemulsification technique.

There is no definite consensus about the ideal time for vitrectomy in the case of nucleus drop, but early vitrectomy which performed within 1 to 2 weeks after cataract surgery could prevent the occurrence of glaucoma, chronic uveitis, and cystoid macular edema. $4,6,8$ Borne et $\mathrm{al}^{9}$ compared vitrectomy performed within two days with one week after cataract surgery, it resulted there were no significant differences in final visual acuity. Salehi et $\mathrm{al}^{10}$, Kim et $\mathrm{al}^{11}$, and Blodi et al ${ }^{12}$ found that vitrectomy performed on the same day or in less than 3 weeks after cataract surgery were both resulted in improvement of visual acuity and reduction in risk of chronic elevated IOP. The meta-analysis by Vanner and Stewart reported significantly better outcomes with early vitrectomy, namely increased in visual acuity and decreased in the incidences of retinal detachment, elevated IOP, and the degree of inflammation/intraocular infection. If vitrectomy cannot be done on the same day, it is recommended to do the surgery within the first week moreover, before performing the surgery, the surgeon has to ensure that the cornea is clear enough to be able to visualize vitreous and retina. ${ }^{13}$

In our hospital, the majority of vitrectomy in nucleus drop cases performed $>2$ weeks after the patient first came to the vitreoretinal clinic, namely in 13 patients (68.4\%). Only $31.6 \%$ of patients were treated by vitrectomy at $\leq 2$ weeks since their first arrival. However, the results showed an increase in the frequency of patients with improved visual acuity. 
The pre-PPV patients with BCVA of $>6 / 45$ were found in $5.3 \%$ of patients and improved to $42.2 \%$ after vitrectomy.

Twenty-three-gauge pars plana vitrectomy is a standard treatment technique that is widely chosen for nucleus drop or IOL drop cases, but in a hard and large-sized nucleus case, a 20-gauge fragmatome is needed. Furthermore, the nucleus can be removed in-toto through the corneal or scleral tunnel. $\mathrm{IOL}$ in the vitreous cavity can be taken using tweezers or vacuum in occlutome, then followed by the removal of the IOL through the corneal or scleral tunnel. ${ }^{7,14}$

The secondary intraocular lens could be inserted directly after the posterior lens mass destroyed by fragmatome. However, in a hard and large-sized estimated lens, the lens should be removed through the anterior ocular camera and the IOL should not be installed first. ${ }^{13,15}$ If the sulcus is stable enough to support the IOL, IOL can be implanted in the sulcus. Selected IOLs for sulcus implantation are foldable IOL and 3-piece PMMA with minimum optical diameter of $6 \mathrm{~mm}$ and minimum total diameter of $13 \mathrm{~mm} .{ }^{15}$ In this study, the IOL was implanted during vitrectomy in 6 patients (31.6\%) and at a different time in 13 patients (68.4\%). Most common location of secondary $\mathrm{IOL}$ implantation in all cases was at iris claw in 10 patients (52.6\%). There is no contraindication of the installation of $\mathrm{IOL}$ conjunction with vitrectomy. The after follow-up visual acuity was not related to the timing of IOL insertion. ${ }^{9}$

The use of Heavy Fluid (HF) can improve the efficiency and safety of the PPV in nucleus drop cases. ${ }^{16} \mathrm{HF}$ can be inserted in the posterior pole, functioning as a protective effect from the ultrasound energy. The ultrasound energy potentially damages important structures such as the macula, optic disc, and large blood vessels at the time of vitrectomy. In large nucleus fragments, enough amount of $\mathrm{HF}$ can be used to lift the entire lens into the upper cavity of vitreous. In aphakic patient, the HF can also be used to float the entire lens to the anterior segment so the lens can be removed through the scleral or corneal tunnel. ${ }^{17}$ HF must be removed after the surgical procedure is complete. In this study, HF was used only in 1 case of dropped IOL because total retinal detachment with PVR occurred while the patient waited for the schedule of operation.

The use of intravitreal triamcinolone acetate (TA) has been carried out for decades because of its function as an anti-inflammatory agent in several intraocular diseases. The advantage of TA as an anti-angiogenic and antifibrotic agent is preventing the growth of fibrous tissue after the intraocular surgery is performed. ${ }^{18,19}$ The use of
TA in PVR surgery associated with refractory uveitis provides a fairly good success rate. ${ }^{20,21}$ Hikichi et al ${ }^{22}$ and Yamakiri et $\mathrm{al}^{23}$ stated that a long term TA residual in the fovea did not have negative effect on anatomy and visual acuity. Furthermore, the usage of TA also reduced the incidence of intraocular complications such as retinal detachment and retinal break. In this study, TA was used at the end of all operation of nucleus drop (100\%).

Corneal edema and uveitis complications cannot be separated from the role of inflammatory mediators triggered by the presence of nucleus fragments in the anterior chamber. In addition, direct mechanical trauma to the cornea caused by nucleus fragments also triggers corneal edema. ${ }^{24}$ In this study, 3 patients (15.8\%) with corneal edema were found. Salehi et al ${ }^{10}$ reported corneal edema in $58.3 \%$ of cases and uveitis in $75 \%$ of cases of nucleus drop, where these conditions made a delay in the PPV procedure because a clearer media is needed to visualize the operation. ${ }^{8,13}$

Salehi et al reported, ${ }^{10}$ elevated IOP in the case of nucleus drop occurred in about $50 \%$ of all cases. IOP elevation, in this case, is associated with intraocular inflammation that is affected by the lens. A clinicopathological study by Yeo et al showed a positive correlation between the degree of response of inflammatory cells to the occurrence of persistent glaucoma. The response of lower inflammatory cells was obtained in the eyes of PPV which performed earlier i.e. less than 1 week. ${ }^{25}$ In this study, 5 patients (14.2\%) had an increase in IOP before PPV was performed.

Romero-Aroca et $\mathrm{a}^{26}$ reported cystoid macular edema (CME) in $31.9 \%$ of nucleus drop cases and was a significant risk factor for patients with post-operative visual acuity $<6 / 12$. Long-term follow-up is needed to determine the occurrence of CME because CME can occur several months after vitrectomy surgery and even persists for many years. ${ }^{10,26}$ We found one patient (2.85\%) with macular edema.

\section{CONCLUSION}

Nucleus drop or IOL drop generally occurs in phacoemulsification cataract surgery technique. Improvement of visual acuity was achieved after PPV and secondary IOL implantation at the end of the follow-up period even though PPV was performed more than 2 weeks after the patient first came to the vitreoretinal clinic in most of the cases. The most common pre-PPV complication was elevated IOP and corneal opacification, whereas most common post-PPV complication was elevated IOP. 


\section{REFERENCES}

1. Williamson TH. Complications of Anterior Segment Surgery. 2013. In: Vitreoretinal Surgery [Internet]. Springer.

2. Mackool RJ, Fishkind WJ, Charles S, Packer M. Managing the Dropped Nucleus. Cataract and Refractive Surgery Today. 2009:80-5.

3. Schaal S, Nesmith BL, Ihnen MA, Al-Latayfeh M. Current Medical and Surgical Management of Retained Lens Fragments After Cataract Extraction. US Ophthalmic Review. 2014;7:95-9.4. Bobrow J, Blecher M, Glasser D, Mitchell K, Rosenberg L, Reich J, et al. Lens and Cataract. 2014. In: Basic and Clinical Science Course [Internet]. American Academy of Ophthalmology; [175-6].

5. Boyd S. Dislocated IOLs and Crystalline Lens. Retinal and Vitreoretinal Diseases and Sugery. Panama: Jaypee; 2010. p. 475-80.

6. Schubert $H$, Atebara $N$, Kaiser $R$, Martidis A, McCannel C, Zacks D, et al. Retinal and Vitreous. Basic and Clinical Science Course: American Academy of Ophthalmology; 2014. p. 357-9.

7. Charles S, Calzada J, Wood B. Vitrectomy Techniques and Technology forAnterior Segment Problems. Vitreous Microsurgery, 5thedition. Philadelphia: Lippincott Williams \& Wilkins; 2011. p. 357-9.

8. Al-Amri AM. Visual outcome of pars plana vitrectomy for retained lens fragments after phacoemulsification. Middle East African journal of ophthalmology. 2008 Jul-Dec;15(3):107-11. PubMed PMID: 21369465.

9. Borne MJ, Tasman W, Regillo C, Malecha M, Sarin L. Outcomes of vitrectomy for retained lens fragments. Ophthalmology. 1996 Jun;103(6):971-6. PubMed PMID: 8643257. Epub 1996/06/01. eng.

10.Salehi A, Razmju H, Beni AN, Beni ZN. Visual outcome of early and late pars plana vitrectomy in patients with dropped nucleus during phacoemulsification. Journal of research in medical sciences : the official journal of Isfahan University of Medical Sciences. 2011;16(11):1422-9. PubMed PMID: 22973342.

11.Kim JE, Flynn HW, Smiddy WE, Murray TG, Rubsamen $P E$, Davis $J L$, et al. Retained Lens Fragments after Phacoemulsification. Ophthalmology. 1994 1994/11/01/;101(11):1827-32.

12.Blodi BA, Flynn HW, Blodi CF, Folk JC, Daily MJ. Retained Nuclei after Cataract Surgery. Ophthalmology. 1992 1992/01/01/;99(1):41-4.

13.Vanner EA, Stewart MW. Vitrectomy timing for retained lens fragments after surgery for age-related cataracts: a systematic review and meta-analysis.
American journal of ophthalmology. 2011 Sep;152(3):345-57.e3. PubMed PMID: 21683330. Epub 2011/06/21. eng.

14.Koh KM, Kim HS, Cho HJ, Lew YJ, Choi MJ, Han Jl, et al. Surgical outcomes of 23-gauge vitrectomy for the management of lens fragments dropped into the vitreous cavity during cataract surgery. Saudi journal of ophthalmology : official journal of the Saudi Ophthalmological Society. 2014;28(4):253-6. PubMed PMID: 25473339. Epub 2014/02/03.

15.Chang DF, Masket $S$, Miller KM, Braga-Mele R, Little BC, Mamalis $N$, et al. Complications of sulcus placement of single-piece acrylic intraocular lenses: recommendations for backup IOL implantation following posterior capsule rupture. Journal of cataract and refractive surgery. 2009 Aug;35(8):144558. PubMed PMID: 19631134. Epub 2009/07/28. eng.

16.Wallace RT, McNamara JA, Brown G, Benson W, Belmont J, Goldberg $R$, et al. The use of perfluorophenanthrene in the removal of intravitreal lens fragments. American journal of ophthalmology. 1993 Aug 15;116(2):196-200. PubMed PMID: 8352305. Epub 1993/08/15. eng.

17.Wong I, Wong D. Special Adjuncts to Treatment. In: Ryan S, editor. Retina (Philadelphia, Pa): Elsevier; 2013. p. 1735-83.

18.Kampougeris G, Cheema R, McPherson R, Gorman C. Safety of Triamcinolone acetonide (TA)-assisted pars plana vitrectomy in macular hole surgery2007. 591-4 p.

19.Jonas JB, Hayler JK, Panda-Jonas S. Intravitreal injection of crystalline cortisone as adjunctive treatment of proliferative vitreoretinopathy. The British journal of ophthalmology. 2000;84(9):1064-7. PubMed PMID: 10966969.

20.Ueno A, Enaida $H$, Hata $Y$, Hisatomi $T$, Nakamura $T$, Mochizuki $Y$, et al. Long-term clinical outcomes and therapeutic benefits of triamcinolone-assisted pars plana vitrectomy for proliferative vitreoretinopathy: a case study. European journal of ophthalmology. 2007 May-Jun;17(3):392-8. PubMed PMID: 17534822. Epub 2007/05/31. eng.

21.Furino C, Micelli Ferrari T, Boscia F, Cardascia N Recchimurzo N, Sborgia C. Triamcinolone-assisted pars plana vitrectomy for proliferative vitreoretinopathy. Retina (Philadelphia, Pa). 2003 Dec;23(6):771-6. PubMed PMID: 14707825. Epub 2004/01/07. eng.

22.Hikichi $T$, Furukawa $Y$, Ohtsuka $H$, Higuchi $M$,

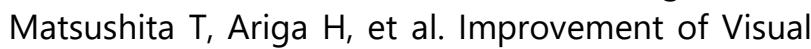
Acuity One-year After Vitreous Surgery in Eyes with Residual Triamcinolone Acetonide at the Macular Hole2008. 267-72 p. 
23.Yamakiri K, Sakamoto T, Noda Y, Nakahara M, Ogino $\mathrm{N}$, Kubota $\mathrm{T}$, et al. Reduced incidence of intraoperative complications in a multicenter controlled clinical trial of triamcinolone in vitrectomy. Ophthalmology. 2007 Feb;114(2):289-96. PubMed PMID: 17270679. Epub 2007/02/03. eng.

24. Kang HM, Park JW, Chung EJ. A retained lens fragment induced anterior uveitis and corneal edema 15 years after cataract surgery. Korean journal of ophthalmology : KJO. 2011;25(1):60-2. PubMed PMID: 21350698. Epub 2011/01/17.

25. Yeo LM, Charteris DG, Bunce C, Luthert PJ, Gregor ZJ. Retained intravitreal lens fragments after phacoemulsification: a clinicopathological correlation. The British journal of ophthalmology. 1999;83(10):1135-8. PubMed PMID: 10502573.

26. Romero-Aroca $P$, Fernández-Ballart J, Méndez-Marín I, Salvat-Serra M, Baget-Bernaldiz M, Buil-Calvo JA. Management of nucleus loss into the vitreous: long term follow up in 63 patients. Clinical ophthalmology (Auckland, NZ). 2007;1(4):505-12. PubMed PMID: 19668529.

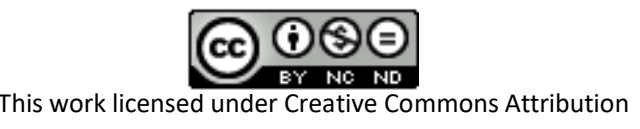

